\title{
I NUOVI ORIZZONTI DELLA SPERIMENTAZIONE SUGLI ESSERI UMANI E SUGLI EMBRIONI ED I MOLTI INTERROGATIVI ETICO-GIURIDICI ANCORA DA SCIOGLIERE
}

\author{
EXPERIMENTATION WITH HUMAN BEINGS AND HUMAN EMBRYOS AND MANY
} ETHICAL-JURIDICAL QUESTIONS TO BE SOLVED

\begin{abstract}
Andre Gonçalo Dias Pereira
Doutor em Direito pela Universidade de Coimbra (2014). Professor Auxiliar da Faculdade de Direito da Universidade de Coimbra.
\end{abstract}

\begin{abstract}
Angelo Viglianisi Ferraro
Doutor pela Facoltà di Giurisprudenza pela Università Mediterranea di Reggio Calabria (2007). Atualmente é Professore e Ricercatore da Università Mediterranea di Reggio Calabria.

Antonio Casciano Doutor em Etica e filosofia politico-juridica pela Università degli studi di Salerno (Italia).
\end{abstract}

\section{Riassunto}

La possibilità di manipolare il genoma umano non è mai stata così vicina, come lo è oggi grazie alla recente evoluzione della tecnologia CRISPR. Le opportunità di superare i problemi di salute o migliorare gli esseri umani sono in esponenziale aumento. Pertanto, il dibattito sulla terapia genica nelle persone umane e negli embrioni umani non è solo un tema rilevante discusso nel mondo accademico, ma un imperativo urgente in tutta la società. L'articolo considera dapprima il quadro normativo offerto dalle diverse convenzioni internazionali esistenti in materia - con un focus dedicato alla legislazione portoghese ed italiana - al fine di far emergere i principi, per lo più di carattere negativo, che ispirano la disciplina in tema di editing genetico. La riflessione si sposta poi sulla considerazione della tematica relativa alla sperimentazione sugli embrioni umani, i cui limiti, nei diversi Stati, risentono della diversità delle visioni morali con le quali si affronta la questione della dignità dell'embrione. Nonostante la varietà di tali posizioni di partenza, è parso possibile fissare taluni divieti accolti in tutti gli ordinamenti. Infine vi è il tema della difficile individuazione di confini chiari utili a distinguere tra l'utilizzazione delle terapie geniche e il diffondersi di una cultura eugenetica vera e propria, il cui rischio pare palesarsi non tanto a livello di scelte 
pubbliche, quanto piuttosto a livello di opzioni che le moderne biotecnologie in tema di procreazione medicalmente assistita mettono a disposizione dei privati cittadini.

Parole-chiave: Cultura eugenetica; Dignità dell'embrione; Sperimentazione scientifica sugli embrioni; Tecnologia CRISPR; Terapia genica.

\begin{abstract}
The possibility of manipulating the human genome has never been so close, due to the recent evolution of CRISPR technology. The opportunities to overcome health limitations or enhance human beings are increasing. Therefore, the debate over gene therapy in human persons and human embryos is not just a relevant theme discussed in the academia, but an imperative of urgency throughout society. The article starts considering the regulatory framework offered by the various international conventions existing on the subject - with a particular focus on Portuguese and Italian legislation - in order to bring out the principles, for the most part negative, that inspire the discipline on genetic editing. Then, the reflection switches on the issue of scientific experimentation on human embryos, the limits of which, in the various states, depend on the different moral visions chosen to approach the question of the dignity of the embryo. However, despite the diversity of these positions, it seemed possible to fix certain prohibitions accepted in all legal systems. Finally, the issue of the difficult identification of clear boundaries to distinguish between the use of gene therapies and the spread of a true eugenics culture, the risk of which seems to be revealed not so much at the public level, but rather at the level of private options that modern biotechnologies about medically assisted procreation make available.
\end{abstract}

Key words: CRISPR technology; Dignity of the Embryo; Eugenics Culture; Gene Therapy; Scientific Experimentation on Embryos.

\title{
1. INTRODUZIONE. I PIÙ RECENTI SVILUPPI IN TEMA DI INGEGNERIA GENETICA
}

L'editing genomico si riferisce a tecniche di ingegneria genetica o di biologia molecolare in cui il DNA viene inserito, cancellato o sostituito nel genoma di un organismo che utilizza enzimi di tipo nucleasi, noti anche come "Forbici molecolari".

Questa procedura può essere eseguita sulla linea somatica o germinale. Nel secondo caso, la modificazione realizzata negli ovuli e nello sperma si trasmette alla prole.

Sono stati descritti finora quattro tecniche di editing, realizzate per mezzo di enzimi alterati dall'azione umana: 1) meganucleasi; 2) nucleasi a dito di zinco; 3) trascrizione nucleasi effettrici simili ad attivatori; e 4) CRISPR (acronimo di Clustered 
Regularly Interspaced Short Palindromic Repeats) e Cas9 (associato a CRISPR).

La CRISPR, in particolare, è un modello relativamente semplice, con costi molto accessibili, attribuito a Francisco Mojica (ricercatore presso l'Università di Alicante), che ha davvero rivoluzionato la materia, in quanto consente di riparare il genoma in specifiche posizioni target (locus), raggiungibili in maniera mirata e programmata ${ }^{1}$, consentendo un elevato grado di precisione nella "cura" di gravi malattie, ovvero nel "miglioramento" (il cosiddetto "potenziamento") del tutto scollegato da qualsiasi esigenza di carattere strettamente terapeutico o medico².

II dibattito su questo tema non è recente: già alla fine del secolo scorso si è avuta una vivace discussione sull'argomento, generata principalmente dalla notizia della clonazione della pecora Dolly (avvenuta nel 1997) ${ }^{3}$.

Tuttavia, eventi recenti hanno reso il confronto ancora più urgente e necessario. Ad esempio, nel 2015, un gruppo di ricercatori dell'Università Sun Yat-sen di Guangzhou, in Cina, guidato da Junjiu Huang, ha effettuato il primo tentativo di modificazione genetica di un embrione umano ${ }^{4}$.

Un anno dopo, un team della Guangzhou Medical University, sempre nello stesso Paese, capeggiato da Yong Fan, ha realizzato un'alterazione delle cellule embrionali per introdurre una modifica che rendesse l'essere umano resistente alle

\footnotetext{
1 Per una migliore comprensione di questa tecnica e del suo potenziale, suggeriamo un articolo di Sander, J., Joung, J. K., "CRISPR-Cas Systems per l'editing, la regolazione e il targeting dei genomi", Nature Biotechnology, 2014, num. 32, pagg. 347-355.

2 Vedi, da ultimo, le scoperte di J Doudna/ E. Carpentier (Premi Nobel per la Chimica 2020), in https://www.nobelprize.org/prizes/chemistry/2020/press-release/.

3 Invero, la nascita dell'ingegneria genetica può essere fatta risalire alla scoperta del DNA ricombinante e dell'endonucleasi di restrizione, un enzima di cui si utilizzano le cellule batteriche per frammentare il DNA virale. Questa scoperta risale agli anni '60 e nel 1978 ha motivato il conferimento del Premio Nobel a Hamilton Smith, Dan Nathans e Werner Arber. In seguito, è stata messa a frutto in termini applicativi da Paul Berg, Herbert Boyer e Stanley Cohen, che nel 1982 hanno ottenuto la sintesi dell'insulina utilizzando batteri geneticamente modificati. Quando gli scienziati compresero le potenzialità di questa tecnologia, sia nella ricerca di base che nelle possibili applicazioni, si arrestarono, più o meno spontaneamente, con una moratoria culminata nel convegno di Asilomar. Nel 1972 si profilò l'idea di applicare questa metodologia nello sviluppo di protocolli di terapia genica. Dopo una sfortunata falsa partenza nel 1980, che coinvolse anche uno scienziato italiano e una paziente italiana, i primi protocolli di terapia genica furono messi a punto alla fine degli anni ' 90 , a partire da quello approvato dalla FDA il 14 settembre 1990 ed immediatamente sperimentato su una bambina affetta da deficit di adenosinadeaminasi (ADA). II parziale successo ottenuto incoraggiò l'applicazione della terapia genica somatica ad altre malattie. Uno degli obiettivi dei ricercatori di quegli anni non era tanto di arrivare a sostituire il gene mutato, quanto di correggerlo in situ, per interferire il meno possibile con la fisiologica funzione della cellula. Un significativo progresso nella precisione dell'inserimento del gene è stato ottenuto dagli studi di Mario Capecchi, Premio Nobel nel 2007, che ha messo a punto tecniche di ricombinazione omologa. Le ricerche hanno da allora proceduto nella direzione di combinare la precisione del gene targeting con una più alta resa in termini di cellule modificate.

${ }_{4}$ Per ulteriori sviluppi, vedere Huang, J. et al., "Editing genico mediato da CRISPR / cas9 negli zigoti tripronucleari umani", Protein Cell, 2015, num. 6 (5), pagg. 363-372.
}

Revista de Direitos Fundamentais \& Democracia, Curitiba, v. 26, n. 1, p. 119-134, jan./abr. 2021. 
infezioni da virus HIV5.

Nell'agosto 2017, i media hanno presentato la prima équipe nordamericana capace di eseguire l'editing genetico negli embrioni umani ${ }^{6}$ e hanno annunciato l'inizio dell'uso commerciale di questa tecnica, in particolare per il trattamento di casi gravi di leucemia, nelle ipotesi in cui i pazienti si siano mostrati refrattari ad altri trattamenti terapeutici? .

Tutti questi eventi paiono legittimare la seguente domanda: è possibile che lo scenario distopico di "Brave New World" (preannunciato nel 1932 da Aldous Huxley) si concretizzi realmente, a distanza di un secolo quasi dalla pubblicazione di quell'opera? II processo di "selezione naturale" sarà effettivamente sostituito da uno di tipo "artificiale"?

Come scrive il pensatore Yuval Harari, oggi l'uomo sembrerebbe voler essere un vero e proprio "Homo Deus", che riesce a trasformare e controllare i connotati dei suoi discendenti ${ }^{8}$. Al punto tale da potersi immaginare, secondo alcuni, la definitiva cessazione dell'età dell'“Homo Sapiens".

Si tratta, in effetti, di questioni complicatissime che impegnano ormai da tempo la filosofia ed il pensiero in generale.

Alcuni autori sono molto cauti riguardo all'uso di queste nuove tecniche: è il caso di Francis Fukuyama ${ }^{9}$ e Jürgen Habermas ${ }^{10}$.

Altri, invece, si sono detti totalmente a favore, come Julian Savulescu, che all'uopo ha messo a punto il principio di "procreative beneficence", in base al quale le coppie, o i singoli interessati alla vicenda procreativa, dovrebbero selezionare il figlio, o i possibili figli, puntando a fare in modo che essi abbiano la vita migliore possibile, o, almeno, una esistenza dignitosa (al pari di quella degli altri) ${ }^{11}$.

5 Cfr. Kang, X. e al., "Introducing precise genetic modifications into human 3PN embryos by CRISPR/Cas-mediated genome editing", Journal of Assisted Reproduction and Genetics, 2016, num. 33, pagg. 581-588.

6 Le notizie in questione sono disponibili su: "http://www.sciencemag.org/news/2017/07/first-us-teamgene-edit-human-embryos-revealed".

${ }^{7}$ L'articolo è reperibile al sito: "https://elpais.com/elpais/2017/07/28/ciencia/1501254013_284569.html". Si noti che la notizia avverte del fatto che ogni iniezione somministrata al paziente può variare tra 250 mila e 500 mila euro.

8 Ci riferiamo a uno dei suoi lavori più recenti: Harari, Y. N., Homo Deus: breve storia di domani, Bompiani, Milano, 2017.

9 Fukuyama, F., Our Posthuman Future: consequences of the biotechnology revolution, Profile Books LTD, Londres, 2002.

10 Habermas, J., The Future of Human Nature, Polity Press, Cambridge, UK, 2003.

11 Savulescu, J., "Procreative beneficience: why we should select the best children", Bioethics, 2001, num. 15 (5-6), pagg. 413-426, nel cui testo introduttivo si legge: «I will defend a principle which I call Procreative Beneficence: couples (or single reproducers) should select the child, of the possible children 


\section{A SPERIMENTAZIONE SUGLI ESSERI UMANI E I DIKTAT DEL DIRITTO SOVRANAZIONALE}

Per quanto riguarda la sperimentazione sugli esseri umani, va subito messo in evidenza un complesso conflitto di valori che emerge ictu oculi: se, da un lato, è necessario proteggere la dignità della persona umana, la vita, l'integrità fisica, l'identità personale e l'autodeterminazione individuale, dall'altra, è necessario garantire la libertà della ricerca, promuovere il progresso della scienza e della medicina, anche al fine di concorrere al miglioramento della salute delle generazioni future.

Le regole etiche e giuridiche sulle quali c'è attualmente un ampio accordo internazionale sono di tipo "negativo": si parla anche di una etica del male minore, il cui obiettivo è tutelare alcuni interessi irrinunziabili della persona dai possibili abusi della sperimentazione.

In linea di massima, come previsto espressamente dall'art. 3 della Carta dei diritti fondamentali dell'Unione Europea, ogni individuo ha diritto alla propria integrità fisica e psichica, per cui qualsiasi intervento condotto su un soggetto, ascrivibile sia all'ambito della medicina che della biologia, deve essere svolto nel rispetto dei seguenti principiguida: il consenso libero e informato dell'interessato, secondo le modalità definite dalla legge, il divieto delle pratiche eugenetiche, in particolare di quelle aventi come scopo la selezione degli individui, il divieto di fare del corpo umano e delle sue parti in quanto tali una fonte di lucro, il divieto della clonazione riproduttiva delle persone.

$\mathrm{Ma}$, il testo normativo più significativo elaborato nel vecchio Continente, in particolare dal Consiglio d'Europa, resta sicuramente la Convention on Human Rights and Biomedicine (c.d. "Convenzione di Oviedo") ${ }^{12}$, approvata il 4 aprile del 1997, dopo un lungo e controverso periodo di discussione (durato oltre 5 anni) ${ }^{13}$.

\footnotetext{
they could have, who is expected to have the best life, or at least as good a life as the others, based on the relevant, available information». Si veda anche Savulescu, J., Kahane, G., "The moral obligation to create children with the best chance of best life", Bioethics, 2009, num. 23 (5), pagg. 274-290.

12 V. Piciocchi, C., "La Convenzione di Oviedo sui diritti dell'uomo e la biomedicina: verso una bioetica europea?", in Diritto Pubblico Comparato ed Europeo, 2001, num. 3, pagg. 1301-1311; Seatzu, F., Fanni, S., "The Experience of the European Court of Human Rights with the European Convention on Human Rights and Biomedicine", in Utrecht Journal of International and European Law, 2015, num. 31(81), pagg. 5-16; Fraissex, P., "La protection de la dignité de la personne et de l'espèce humaines dans le domaine de la biomédecine: l'exemple de la Convention d'Oviedo", in Rev. intern. dr. comp., 2000, num. 2, pagg. 371 ss.; Gitti, A., "La Corte Europea dei diritti dell'uomo e la Convenzione sulla biomedicina", in Riv. internaz. dir. uomo, 1998, num. 1, pagg. 719 ss.

13 I redattori della Convenzione recepiscono i "desiderata" contenuti nella risoluzione n. 3 adottata dai
} 
Come è stato rilevato in dottrina, il documento sembra voler configurare un organico "diritto europeo in materia di bioetica"14, ponendo un argine normativo robusto alla disorganicità esistente in materia nel Vecchio Continente.

Assume, da questo punto di vista, primario significato il contenuto dell'art. 2, che, nel ribadire il principio della dignità inalienabile dell'essere umano, così statuisce: «L'interesse e il bene dell'essere umano debbono prevalere sul solo interesse della società o della scienza».

Ma, degne di nota sono anche altre disposizioni presenti nei primissimi articoli del documento normativo in questione, e dedicati a temi cruciali quali: il diritto all'accesso alle cure sanitarie; gli obblighi professionali e regole di condotta degli operatori sanitari; la protezione delle persone che non hanno la capacità di fornire il proprio consenso; la tutela delle persone che soffrono di un disturbo mentale; le situazioni di urgenza; i desideri precedentemente espressi ${ }^{15}$.

La disposizione più controversa, e che ha acceso maggiori dibattiti, è certamente quella contenuta nell'art. 18, nel quale - con una formula "di compromesso"16 - si è stabilito che: «1. Quando la ricerca sugli embrioni in vitro è ammessa dalla legge, questa assicura una protezione adeguata all'embrione. 2. La costituzione di embrioni umani a fini di ricerca è vietata» ${ }^{17}$.

Nel 1998, il Consiglio d'Europa ha aggiunto alla Convenzione in questione un

Ministri della Giustizia, su proposta del Segretario generale del Consiglio d'Europa (1990) e nella Raccomandazione n. 1160 (1991) dell'Assemblea parlamentare, diretti a costituire una "framework convention comprising a main text" completa in materia.

14 Piciocchi, C. op. cit., pag. 1301.

15 Cfr., per tutti, l'art. 11, che si occupa del divieto di ogni forma di discriminazione in ragione del patrimonio genetico del singolo individuo; l'art. 12, che vieta i test genetici predittivi di malattie genetiche o che permettano sia di identificare il soggetto come portatore di un gene responsabile di una malattia sia di rivelare una predisposizione o una suscettibilità genetica a una malattia se non a fini medici o di ricerca medica, e sotto riserva di una consulenza genetica appropriata; l'art. 13 che limita la possibilità di effettuare interventi manipolativi del Genoma Umano per ragioni preventive, diagnostiche o terapeutiche e sempre che abbiano come scopo l'introduzione di una modifica nel genoma dei discendenti: l'art. 14 che stabilisce l'inammissibilità di tecniche di assistenza medica finalizzate a scegliere il sesso del nascituro (salvo che per evitare una malattia ereditaria legata al sesso).

16 Questa l'espressione usata nello Studio finale su "Le implicazioni etiche della ricerca sugli embrioni umani", pubblicato nel 2000 dalla Direzione Generale degli Studi, Divisione Industria, ricerca e energia STOA (Scientific and Technological Options Assessment) del Parlamento Europeo, alla cui pag. 57 si legge: «L'articolo 18 della Convenzione sulla bioetica è stato uno degli argomenti più controversi discussi durante l'approvazione del documento formale e il punto cruciale di molti documenti rielaborati. Questo carattere controverso è palese nella natura di compromesso della disposizione finale».

17 Da più parti è stata fatta notare la difficoltà di comprensione della definizione formulata. Cfr. Gunning, J., "La convenzione europea sui diritti umani e la biomedicina: conflitti e conseguenze nell'area della riproduzione assistita", in Bioetica, 1998, num. 4, pagg. 527 ss. Secondo Piciocchi, C., op. cit., pag. 1303, «il forzato consenso su tale statuizione lascia dubitare della sua operatività destinata o ad essere disattesa, o ad essere interpretata in tanti modi diversi quante saranno le possibili interpretazioni dettate dall'ordinamento statale nell'ambito del quale sarà applicata».

Revista de Direitos Fundamentais \& Democracia, Curitiba, v. 26, n. 1, p. 119-134, jan./abr. 2021. 
Protocollo, riguardante the Application of Biology and Medicine on the Prohibition of Cloning Human Beings, che vieta espressamente di usare la tecnologia della clonazione sugli esseri umani ${ }^{18}$.

Ed il 25 gennaio 2005 è stato inserito un secondo Additional Protocol to the Oviedo Convention concerning Biomedical Research, nel cui art. 2 si è chiarito che il testo "copre l'intera gamma di attività di ricerca in campo sanitario che coinvolgono interventi sugli esseri umani», ma «non si applica alla ricerca sugli embrioni in vitro», bensì solo a quella «su feti ed embrioni in vivo» ${ }^{19}$.

Meritevoli di segnalazione sono, del resto, le innumerevoli norme esistenti a livello internazionale con riguardo alle sperimentazioni cliniche di nuovi farmaci praticate sugli esseri umani ${ }^{20}$ e le tante dichiarazioni dell'UNESCO in materia di interventi sul genoma umano ${ }^{21}$.

Certamente, è possibile affermare che il "pensiero di base" di tutti questi standard internazionali ed europei sia ben rappresentato e sintetizzato nella legge portoghese n. 21 del 16 aprile 2014 (la cosiddetta "Legge sulla ricerca clinica"), secondo la quale è possibile condurre studi laboratoriali (su soggetti umani) che implichino l'uso di farmaci per la terapia genica, ovvero, la terapia cellulare somatica o che contengano organismi geneticamente modificati ${ }^{22}$.

\footnotetext{
18 II Protocollo stabilisce che: «1. Any intervention seeking to create a human being genetically identical to another human being, whether living or dead is prohibited. 2. For the purposes of this article, the term human being "genetically identical" to another human being means a human being sharing with another the same nuclear gene set». La Relazione che accompagna il testo si preoccupa, però, di chiarire che "this Protocol does not take a specific stand on the admissibility of cloning cells and tissue for research purposes resulting in medical applications. However, it can be said that cloning, as a biomedicinal technique is an important tool for the development of medicine [...]. The provisions in this Protocol shall not be understood as prohibiting cloning techniques in cell biology».

19 Così nell'articolo 2 dell'Additional Protocol to the Convention on Human Rights and Biomedicine, concerning Biomedical Research, pubblicato dal Consiglio d'Europa il 25 gennaio 2005, il cui testo recita: «This Protocol covers the full range of research activities in the health field involving interventions on human beings. This Protocol does not apply to research on embryos in vitro. It does apply to research on foetuses and embryos in vivo».

20 Si veda, in questo senso, il Codice di Norimberga del 1947, la Dichiarazione di Helsinki della World Medical Association, scritta nel 1964 - dove fu stabilita una serie di principi etici per la ricerca medica sugli esseri umani - o il Patto internazionale sui diritti civili e politici, creati dalle Nazioni Unite nel 1966 (nel cui art. 7 si legge che «in particolare, nessuno sarà sottoposto senza il suo libero consenso a esperimenti medici o scientifici»). Si aggiungano le Linee guida internazionali di CIOMS/OMS, come quelle relative alle "International Ethical Guidelines for Health-Related Research Involving Humans", pubblicate nel 2016 e disponibili al sito: https://cioms.ch/wp-content/uploads/2017/01/WEB-CIOMSEthicalGuidelines.pdf.

21 Dichiarazione universale sul genoma umano e sui diritti umani, dell'11 novembre 1997; Dichiarazione internazionale sui dati genetici umani, del 16 ottobre 2003; Dichiarazione universale di bioetica e diritti umani, del 19 ottobre 2006.

22 La legge richiede tuttavia che gli studi clinici debbano essere preceduti da un parere favorevole del Comitato etico competente, da emettere entro 30 giorni, senza del quale lo studio non può essere condotto (art. 16). A sua volta, l'articolo 17/2/3 stabilisce la possibilità di prorogare il termine entro il quale
}

Revista de Direitos Fundamentais \& Democracia, Curitiba, v. 26, n. 1, p. 119-134, jan./abr. 2021. 
In Italia, al momento, l'applicazione del gene editing alle cellule germinali è vietata dalla legge 40/2004, recante "Norme in materia di procreazione medicalmente assistita", il cui articolo 13 consente la ricerca sugli embrioni per «finalità esclusivamente terapeutiche e diagnostiche ad essa collegate volte alla tutela della salute e allo sviluppo dell'embrione stesso, e qualora non siano disponibili metodologie alternative». Viene, dunque, vietata «ogni forma di selezione a scopo eugenetico degli embrioni e dei gameti ovvero interventi che, attraverso tecniche di selezione, di manipolazione o comunque tramite procedimenti artificiali, siano diretti ad alterare il patrimonio genetico dell'embrione o del gamete ovvero a predeterminarne caratteristiche genetiche».

Tuttavia, la Corte Costituzionale, con la storica sentenza n. 96/2015, ha escluso dalle restrizioni ivi contemplate l'accesso alla diagnosi pre-impianto per le coppie portatrici di geni associati a malattie genetiche gravi. Sono invece sempre ammesse le terapie geniche su cellule somatiche, sia eseguite secondo la tecnica "ex vivo" consistente nel prelevare le cellule somatiche della persona interessata e metterle in coltura; le cellule vengono poi "trasfettate" con il gene d'interesse, inserito tramite un apposito vettore (spesso vengono usati vettori virali) e successivamente reinfuse o reinmpiantate nel corpo del soggetto -, sia eseguite mediante la tecnica "in vivo" attuata viceversa in tutti quei casi in cui le cellule non possono essere messe in coltura o prelevate e reimpiantate, come ad esempio quelle del cervello o del cuore e della maggior parte degli organi interni, per cui il gene viene inserito nell'organismo tramite un apposito vettore, direttamente per via locale o sistemica.

Le obiezioni in generale mosse all'impiego del gene editing applicato alle cellule somatiche sono: la possibilità che si sviluppino reazioni immunitarie secondarie

questo parere deve essere concesso, fino ad un periodo massimo di 20 giorni o di 50 , in caso di consultazione con gruppi o comitati di esperti. Si può inoltre leggere al paragrafo 4 che il parere sugli studi clinici che implicano l'uso di farmaci per terapia cellulare xenogenici non è soggetto a nessuna scadenza. In base a questa legge, importanti studi clinici sono stati condotti nell'area dell'ematologia e della dermatologia. Oltre al parere obbligatorio emesso dalle Commissioni etiche, la legge stabilisce, all'art. 27, che «gli studi clinici che coinvolgono i seguenti trattamenti dipendono sempre dall'autorizzazione espressa: a) terapia genica; (b) terapia cellulare somatica; (c) terapia contenente organismi geneticamente modificati; (d) terapia cellulare xenogenica». La richiesta di autorizzazione per eseguire queste prove deve essere presentata a INFARMED, I.P., ai sensi dell'art. 26. Ma, sebbene la legge consenta, in presenza di determinati, specifici requisiti, la terapia nella linea cellulare somatica, lo stesso non può dirsi con la terapia nella linea cellulare germinale, cioè in quella trasmessa ai propri discendenti. In questo caso, l'art. 27/6 è chiaro nell'affermare che «non possono essere condotti studi sulla terapia genica che possano dar luogo a cambiamenti nell'identità genetica della linea germinale del partecipante». Questo è ciò che indica la Convenzione di Oviedo, nel suo art. 13, quando afferma che «un intervento il cui scopo è modificare il genoma umano non può essere effettuato se non per ragioni preventive, diagnostiche o terapeutiche e solo se non si intende introdurre una modifica nel genoma della prole».

Revista de Direitos Fundamentais \& Democracia, Curitiba, v. 26, n. 1, p. 119-134, jan./abr. 2021. 
all'introduzione del vettore (virus), utilizzato per veicolare il gene all'interno della cellula, che è geneticamente estraneo all'ospite; il timore che i vettori modificati non raggiungano solo le cellule bersaglio della terapia, ma anche altre cellule e tessuti, eventualmente colonizzando le cellule germinali; l'eventualità che il vettore riacquisisca la capacità infettante e diventi patogeno per l'ospite; il rischio che il "nuovo" gene venga inserito in una porzione sbagliata del genoma inducendo forme patologiche non prevedibili.

Si tratta complessivamente di ipotesi oggi relativamente remote (in quanto le esperienze acquisite nei primi, pionieristici anni della terapia genetica hanno permesso di sviluppare protocolli affidabili e sicuri), ma il tema continua a creare molti dubbi in dottrina.

Gli interventi sulla linea cellulare germinale sono invece generalmente vietati dalla legge in maniera espressa.

Questa è la posizione seguita non solo dalla legislazione nazionale in questo campo, ma anche da quella internazionale ed europea attualmente vigente.

Tuttavia, di recente, la netta distinzione delle problematiche etiche tra la modifica della linea germinale e di quella somatica è stata messa in discussione da alcuni studiosi, poiché almeno talune criticità si sovrappongono.

Così è per la difficoltà di circoscrivere le applicazioni del gene editing agli usi terapeutici, stante la crescente difficoltà a distinguere tra usi terapeutici e non terapeutici (di enhancement), in uno scenario di sviluppo della medicina sempre più orientata verso la prevenzione; e così è per la possibile modificazione (seppur difficilmente immaginabile) delle cellule germinali nel gene editing delle cellule somatiche, che, per quanto "effetto indesiderato", si tradurrebbe comunque in un'alterazione del patrimonio genetico dei discendenti.

A causa anche delle incomprensioni esistenti sulla natura e sul significato stessi della ricerca medica, i ricercatori hanno iniziato ad osservare spesso il solo obbligo morale di prestare particolare attenzione nell'ottenimento del consenso degli utenti, evitando tutte le forme di inganno o di coercizione (diretta o indiretta).

Occorre però chiedersi se non sia necessario intervenire normativamente per disciplinare in maniera più dettagliata la materia (sottraendola, almeno in parte, alla decisione dei privati), partendo dal presupposto che la dignità della persona (valore primario e assoluto di ogni ordinamento giuridico) e i diritti inviolabili ad essa inerenti devono costituire sempre un limite insormontabile ad alcune tipologie di 
sperimentazione clinica (pur in presenza di un chiaro consenso di segno contrario dei singoli individui interessati a fornire il proprio corpo per la finalità in questione).

\section{L A SPERIMENTAZIONE SUGLI EMBRIONI UMANI}

Ben più complesso è poi il tema della sperimentazione sull'embrione umano, per finalità di natura scientifica o terapeutica (anche per l'ovvia impossibilità di acquisire un consenso da parte del diretto interessato).

La facilità con la quale si possono ormai produrre embrioni e la disponibilità di una crescente quantità di questi ultimi in sovrannumero, legate ai rapidi sviluppi della scienza e alla caduta di alcune limitazioni normative in materia, hanno prodotto notevoli pressioni per il loro utilizzo anche, quantunque non esclusivamente, a fini di ricerca scientifica.

Si possono distinguere tre tipi di motivazioni che tradizionalmente vengono addotte a favore della sperimentazione sugli embrioni.

In primo luogo, ci sono finalità terapeutiche. La ricerca sull'embrione è necessaria per comprendere, ad esempio, il fenomeno della sterilità (squilibrio ormonale, ecc.), i cambiamenti biochimici tra l'embrione e l'ambiente (al fine di migliorare il trasferimento dell'embrione); anomalie genetiche o acquisite nell'embrione; le caratteristiche genetiche di quest'ultimo, che consentono di prevedere l'insorgenza di una malattia con metodi di biologia molecolare (diagnosi preimpianto, medicina predittiva); la correzione delle malattie genetiche mediante modificazione genetica dell'embrione (terapia genica germinale), consistente nel liberare i discendenti di persone affette da malattie ereditarie dalle modificazioni genetiche che hanno provocato tali malattie.

In secondo luogo, ci sono motivazioni scientifiche in senso stretto, che vedono nella sperimentazione una straordinaria possibilità di acquisire nuove conoscenze nel settore. I modelli delle indagini che si fanno sull'embrione animale danno una idea di quelle che potrebbero essere effettuate sull'embrione umano. Alcune ricerche cercano, ad esempio, di comprendere, a diversi livelli (cellulare, genetico, molecolare), gli eventi dell'embriogenesi animale (moltiplicazione cellulare, differenziazione delle forme, funzioni specializzate dell'organismo, ecc.). Altre sono di natura sperimentale pratica, come la coltura in vitro dell'embrione; la fecondazione interspecie; la ricostituzione dell'embrione mediante micromanipolazione; la selezione del sesso; il trasferimento 
nucleare (clonazione); l'induzione di modificazioni nel patrimonio genetico degli embrioni (animali transgenici); i miglioramenti nella fecondazione in vitro; o l'uso di determinati tessuti (ad esempio quello ovarico) da donatori nella ricerca sull'embrione o nel trattamento dell'infertilità.

In terzo luogo, ci sono obiettivi legati all'industrializzazione e alla commercializzazione, che in alcuni casi possono anche riguardare il settore cosmetico ed alimentare nei Paesi del terzo mondo. La produzione di embrioni umani a fini di ricerca o per il mercato del trasferimento di embrioni potrebbe essere indirizzata alla creazione di banche di embrioni con l'obiettivo di utilizzarli in un mercato per trapianti di tessuto e per cellule fetali differenziate o meno. In alcuni Paesi sono già stati effettuati trapianti sperimentali di tessuto fetale per il morbo di Parkinson.

Quanto sin qui evidenziato restituisce già un sintetico quadro dell'ampiezza dei problemi etici che possono nascere in relazione alle molteplici possibilità di sperimentazione sull'embrione umano.

La maggior parte dei comitati nazionali (ad es. di Gran Bretagna, Germania, Francia, ecc.) si è mostrata favorevole ad un piano etico che consenta - sia pure molto limitatamente - la realizzazione di alcune attività di questo tipo. Ciascun comitato ha cercato di conciliare il principio della libertà di ricerca con quello del rispetto della vita umana, stabilendo per lo più che la conoscenza acquisita deve essere essenzialmente di natura terapeutica (e avere un'utilità diretta, sia per l'embrione stesso che per la società).

In Italia, in particolare, il Comitato Nazionale di Bioetica, già nel documento su "Identità e statuto dell'embrione umano", del 27 giugno 1996, era pervenuto unanimemente a riconoscere il dovere morale di trattare il concepito - sin dalla fecondazione - secondo i criteri di rispetto e tutela che si devono adottare nei confronti degli individui umani, ai quali si attribuisce comunemente la caratteristica di persone; e nel 2003 ha ribadito la propria posizione, sottolineando che «gli embrioni umani sono vite umane a pieno titolo» e che "esiste quindi il dovere morale di sempre rispettarli e sempre proteggerli nel loro diritto alla vita, indipendentemente dalle modalità con cui siano stati procreati e indipendentemente dal fatto che alcuni di essi possano essere qualificati - con una espressione discutibile, perché priva di valenza ontologica soprannumerari» ${ }^{23}$.

${ }^{23}$ Si tratta del parere del CNB su "Ricerche utilizzanti embrioni umani e cellule staminali" dell'11 aprile 2003, reso in relazione alle richieste avanzate dal Ministro Moratti, in occasione dell'avvio del VI 
Certamente, vale la pena ricordare che, nonostante ci siano molte correnti dottrinali in tutta Europa favorevoli ad affermare la necessità di considerare l'embrione una persona umana a tutti gli effetti, un'analisi puramente giuridica dei sistemi giuridici portoghese ed italiano consente di negare tale possibilità.

In primis, l'art. 66 del codice civile portoghese condiziona l'acquisizione della personalità giuridica alla "nascita piena e viva", non riconoscendola al "nasciturus" o "concepturus"24. Si noti che ciò non significa necessariamente che l'embrione non goda di alcuna protezione giuridica all'interno del sistema normativo. Il codice penale portoghese, ad esempio, distingue tra "crimini contro la vita" e "crimini contro la vita intrauterina", suggerendo che i due beni protetti sono autonomi e da non confondere.

Ancora più significative sono le linee-guida fornite dalla giurisprudenza della Corte costituzionale portoghese, relativa alle questioni più varie ${ }^{25}$, dalle quali emerge chiaramente che è necessario distinguere, sul piano strettamente giuridico, le persone dagli embrioni, nonostante debba essere riconosciuto che anche gli embrioni godono di una protezione costituzionale, anche se limitata ${ }^{26}$. Vale la pena menzionare la sentenza

Programma Quadro di Ricerca dell'UE, e concernenti la liceità, dal punto di vista etico, della possibilità di: a) svolgere sul territorio nazionale ricerche utilizzanti embrioni umani anche soprannumerari che ne determinino la distruzione; b) svolgere ricerche utilizzanti cellule staminali derivate da embrioni umani prodotte in data successiva all'avvio del VI Programma Quadro di Ricerca dell'Unione Europea; c) produrre cellule staminali derivate da embrioni umani anche soprannumerari. II Comitato ha espresso parere negativo rispetto a tutti e tre i quesiti, considerando che: «e) che l'eventuale finanziamento pubblico alla ricerca sugli embrioni non può che rafforzare e avallare ingiustificatamente l'erronea opinione che gli embrioni siano un mero insieme di cellule, prive di valore intrinseco, e quindi conseguentemente l'idea dell'irrilevanza bioetica della vita umana nella fase embrionale; f) che la limitazione della sperimentazione agli embrioni soprannumerari, oltre a non avere motivazione logica, ma solo occasionale e pragmatica, favorirebbe surrettiziamente la pratica di produzione di embrioni in vitro a soli scopi di ricerca, indipendentemente cioè da specifiche finalità inerenti alla fecondazione assistita e in violazione quindi di consolidati principi bioetici; g) che il prelievo di cellule staminali umane da embrioni, comportando la distruzione di questi ultimi, deve essere a pari titolo stigmatizzato, anche per l'ulteriore effetto eticamente inaccettabile di non orientare la ricerca verso la sempre più promettente ed eticamente impeccabile utilizzazione di cellule staminali prelevate da cordone ombelicale o da feti spontaneamente abortiti o di cellule staminali "adulte"».

${ }^{24}$ Anche all'interno della dottrina portoghese, e nonostante il significato letterale dell'art. 66 del CC, c'è chi crede che il nascituro sia dotato di personalità giuridica; all'uopo, cfr. Oliveira Ascensão, J., Estudos de Direito da Bioética, Vol. II, Almedina, Portugal, 2008, pag. 26.

25 Spiccano le seguenti sentenze della Corte costituzionale portoghese: Sentenza TC n. 25/84, del 23 aprile (relativa alla depenalizzazione dell'aborto in alcuni casi, come i reati contro la libertà sessuale, i rischi per la salute o la vita della madre, le malformazioni gravi dell'embrione); Sentenza TC 85/85, del 29 maggio (relativa a questioni analoghe relative alla depenalizzazione dell'aborto); Sentenza TC n. 288/98, del 17 aprile (relativa al primo referendum sull'aborto); Sentenza TC n. 617/2006, del 15 novembre (relativa al secondo referendum sull'aborto); e Decisione TC 101/2009, del 3 marzo (relativa alla costituzionalità dell'articolo 9 della legge che regola la procreazione medicalmente assistita - Legge 32/2006).

${ }^{26}$ E si nota, come affermano alcuni autorevoli studiosi, che «la protezione della vita intrauterina non deve essere identica in tutte le fasi del suo sviluppo, dalla formazione dello zigote alla nascita». Così Gomes Canotilho, J.J., Moreira, V., Constituição da República Portugesa Anotada, Vol I, 4a ed., Coimbra Editora, Coimbra, 2014, pag. 449.

Revista de Direitos Fundamentais \& Democracia, Curitiba, v. 26, n. 1, p. 119-134, jan./abr. 2021. 
n. 101/2009, del 3 marzo, in cui il Tribunale costituzionale portoghese ha affermato che «l'embrione non impiantato non ha le garanzie della vita umana, come risorsa costituzionalmente protetta o alcuno dei diritti della personalità, come il diritto integrità fisica 0 diritto all'integrità genetica e all'identità personale» ${ }^{27}$.

Si può, quindi, affermare che la Costituzione portoghese non si oppone alla ricerca sugli embrioni.

Come segnalato altrove, la situazione è simile in Italia ${ }^{28}$.

Chiamata, qualche anno fa, a pronunciarsi sulla legittimità costituzionale di vari articoli della legge 40/2004 in tema di Procreazione medicalmente assistita, la Corte costituzionale italiana, con la sentenza n. 151/200929, ha dichiarato illegittimo l'art. 14, comma $2^{\circ}$ del testo legislativo in questione, limitatamente alle parole «ad un unico e contemporaneo impianto, comunque non superiore a tre» e altresì il comma $3^{\circ}$ del medesimo articolo, nella parte in cui non ha previsto che il trasferimento degli embrioni, da realizzare non appena possibile, come stabilito in tale norma, debba essere

${ }^{27}$ Questo è quanto si legge nel testo originale della Sentenza del Tribunale costituzionale portoghese $\mathrm{n}$. 101/2009: «O ponto essencial, como aí se explanou, é que a investigação científica nos termos previstos no artigo $9 .^{\circ}$ incide sobre embriões não implantados no útero materno e relativamente aos quais se não colocam questões de constitucionalidade relacionadas com o direito à vida ou os direitos de personalidade, sendo apenas de considerar a protecção do embrião na perspectiva da dignidade da pessoa humana na estrita medida em que o embrião poderia dar origem a uma vida humana se fosse viável e viesse a ser utilizado num projecto parental. E deste ponto de vista, o regime legal condensado na referida disposição do artigo $9 .{ }^{\circ}$ oferece já uma adequada protecção. Note-se, antes de mais, que a norma proíbe a criação de embriões com o objectivo deliberado de utilização na investigação científica (n. ${ }^{\circ}$ 1). Por outro lado, salvo a previsão constante do artigo $9 .^{\circ}, n .{ }^{\circ} 4$, alínea d), que será objecto de tratamento autónomo, só poderão ser aplicados na investigação os embriões, criados para fins de procriação medicamente assistida, que não tenha sido possível enquadrar num projecto parental, ou por não terem sido utilizados pelo casal e este não ter autorizado a sua doação nos termos dos artigos $10 .^{\circ}$ e $25 .^{\circ}, n .{ }^{\circ} 5$, ou por se terem tornado inviáveis (em virtude de o seu estado não permitir a transferência ou a criopreservação com vista à procriação), ou ainda por serem portadores de anomalia genética grave (artigo $9 .^{\circ}, n{ }^{\circ} 4$, alíneas a) a c). Por fim, importa considerar que a investigação com recurso a embriões só é lícita para qualquer das finalidades mencionadas no n. 2 do artigo $9 .^{\circ}$ (prevenção, diagnóstico ou terapia de embriões, aperfeiçoamento das técnicas de PMA, constituição de bancos de células estaminais para programas de transplantação ou com quaisquer outras finalidades terapêuticas) e, como determina o n. 3 , desde que seja razoável esperar que daí possa resultar benefício para a humanidade».

${ }^{28}$ Cfr. D'Alvia, D., Viglianisi Ferraro, A., "The (Legal) Qualification of the Embryo and Its Utilization for Scientific Research Purposes Under the European Multilevel Protection System of Fundamental Rights", in European Review of Private Law, 2018, num. 26 (3), pagg. 421 - 443.

29 La sentenza, adottata l'8 maggio 2009, è reperibile in Fam. dir., 2009, pag. 761, con nota di Dogliotti, M., "La Corte costituzionale interviene sulla produzione e sul trasferimento degli embrioni a tutela della salute della donna". Ma, v. anche Ferrando, G., "Fecondazione in vitro e diagnosi preimpianto dopo la decisione della Corte Costituzionale", in Nuova giur. civ. comm., 2009, XI, pagg. 521 ss.; Dolcini, E., op. cit., pagg. 950 ss.; Turillazzi, E., "Continua "l'intervento demolitorio" operato dalla Corte Costituzionale alla legge 40/2004: tra libertà, uguaglianza, tutela della salute della donna e libertà conoscitiva della scienza medica", in Riv. it. med. leg., 2009, pagg. 767 ss.; Razzano, G., "L'essere umano allo stato embrionale e $\mathrm{i}$ contrappesi alla sua tutela. In margine alla sentenza della Corte costituzionale $\mathrm{n}$. 151/2009 e all'ordinanza del Tribunale di Bologna del 29 giugno 2009", in Giur. it., 2010, pagg. 2 ss.; Agosta, S., "Dalla Consulta finalmente una prima risposta alle più vistose contraddizioni della disciplina sulla fecondazione artificiale", reperibile al sito: www.forumcostituzionale.it.

Revista de Direitos Fundamentais \& Democracia, Curitiba, v. 26, n. 1, p. 119-134, jan./abr. 2021. 
effettuato senza pregiudizio della salute della donna ${ }^{30}$. Tali conclusioni - ha aggiunto poi la Corte - introducono di fatto «una deroga al principio generale di divieto di crioconservazione di cui al comma 1 dell'art. $14 »^{31}$. La conseguenza di tale sentenza è stata l'ampliamento del numero degli embrioni residuali non trasferibili, che si è poi ulteriormente allargato per effetto della successiva sentenza n. 96 del 2015², la quale nel dichiarare l'illegittimità costituzionale degli artt. 1, commi 1 e 2, e 4, comma 1, della legge n. 40 del 2004, nella parte in cui non consentivano il ricorso alle tecniche di procreazione medicalmente assistita alle coppie fertili, portatrici di malattie genetiche trasmissibili - ha con ciò reso possibile la diagnosi preimpianto, al fine appunto di evitare il trasferimento, in utero della donna, degli embrioni affetti da siffatte patologie genetiche (per i quali anche risulta, di conseguenza, derogato il divieto di crioconservazione).

L'11 novembre dello stesso anno, poi, con la sentenza n. 22933, la Corte costituzionale italiana è intervenuta nuovamente in materia, stabilendo l'illegittimità costituzionale dell'art. $13,3^{\circ}$ comma, lett. b) e 4 della Legge n. 40/2004, nella parte in cui contempla come ipotesi di reato la condotta di selezione degli embrioni anche nei casi in cui questa sia esclusivamente finalizzata a evitare l'impianto nell'utero della donna di ovuli fecondati affetti da malattie genetiche trasmissibili rispondenti ai criteri di gravità di cui all'art. 6, $1^{\circ}$ comma, lett. b), della legge n. 194/1978 sull'aborto e accertate da apposite strutture pubbliche. La Corte ha, invece, contestualmente escluso la

30 Come ha ben evidenziato Perrone, G., op. cit., «nei casi di signore oltre una certa età, dunque, diminuivano notevolmente le possibilità di successo delle tecniche mediche e l'obbligo di ripartire con un ulteriore ciclo di stimolazioni ovariche nel caso di primo insuccesso metteva in pericolo la loro salute; per le donne più giovani, al contrario, l'obbligo di un "unico e contemporaneo impianto" comportava il rischio di gravidanze plurime con conseguenze potenzialmente dannose per loro stesse e per i futuri feti».

31 Con decreto del 25 giungo 2009, il Ministro della Salute ha nominato una Commissione di studio sugli embrioni crioconservati nei centri di procreazione medicalmente assistita. Nella relazione finale di tale commissione (www.salute.gov.it/imgs/C_17_minpag_658_documenti_documento_1_fileAllegatoDoc.pdf), adottata a maggioranza l'8 gennaio 2010, è esposto quanto segue: «ll divieto legale di soppressione degli embrioni induce a ritenere che la crioconservazione possa essere interrotta solo in due casi: quando si possa impiantare l'embrione scongelato nell'utero della madre o comunque di una donna disposta ad accoglierlo, o quando sia possibile accertarne scientificamente la morte naturale o la definitiva perdita di vitalità come organismo. Allo stato attuale delle conoscenze, per accertare la perdurante vitalità dell'embrione è necessario però scongelarlo, il che ci pone di fronte ad un paradosso, dato che una volta scongelato l'embrione non può essere congelato una seconda volta e se non si provvede ad un suo immediato impianto in utero, se ne causa inevitabilmente la sua morte. Di qui la prospettiva tuzioristica di una possibile conservazione a tempo indeterminato degli embrioni congelati».

$32 \mathrm{Si}$ tratta della pronuncia del 5 giugno 2015, reperibile in Nuova giurisprudenza civile commentata, 2015, II, pagg. 582 ss., con commento di Ferrando, G., "Come d'autunno sugli alberi le foglie. La legge n. 40 perde anche il divieto di diagnosi preimpianto".

${ }^{33}$ La pronuncia è stata commentata, inter alios, da Porracciolo, A., "Fecondazione: quella contraddizione delle sanzioni penali", in Guida al dir., 2015, num. 48, pagg. 16 ss.; Vallini, A., "Ancora sulla selezione preimpianto: incostituzionale la fattispecie di selezione embrionale per finalità eugenetiche, ma non quella di embrionicidio", 12/2015, reperibile in www.penalecontemporaneo.it.

Revista de Direitos Fundamentais \& Democracia, Curitiba, v. 26, n. 1, p. 119-134, jan./abr. 2021. 
fondatezza della questione di legittimità costituzionale dell'art. 14, commi 1 e 6, della Legge 40 , che vieta penalmente, sanzionandola, la condotta di soppressione degli embrioni (anche se affetti da malattia genetica) ${ }^{34}$. Secondo il giudice delle leggi, "la malformazione" dell'entità creata in vitro non ne giustifica, solo per questo, un "trattamento deteriore" (o una "tutela affievolita") rispetto a quello degli embrioni sani. Per quelli ammalati non impiantabili non si prospetta, «allo stato, altra risposta che la procedura di crioconservazione. L'embrione, infatti, quale che sia il più o meno ampio riconoscibile grado di soggettività correlato alla genesi della vita, non è certamente riducibile a mero materiale biologico». Per la Corte costituzionale italiana, dunque, la dignità dell'embrione, quale entità che ha in sé il principio della vita, ancorché in uno stadio di sviluppo non predefinito dal legislatore e tuttora non univocamente individuato dalla scienza, costituisce, comunque, un valore di rilievo costituzionale riconducibile al precetto generale dell'art. 2 della Carta fondamentale italiana.

In Portogallo, la legge n. 32/2006, sulla procreazione medicalmente assistita, nel suo art. 9 afferma «é proibida a criação de embriões através da PMA com o objectivo deliberado da sua utilização na investigação científica».

Ma, subito dopo, al secondo comma, è contenuta una specificazione importante, in base alla quale, va considerata «lícita a investigação científica em embriões com o objectivo de prevenção, diagnóstico ou terapia de embriões, de aperfeiçoamento das técnicas de PMA, de constituição de bancos de células estaminais para programas de transplantação ou com quaisquer outras finalidades terapêuticas» ${ }^{35}$.

Se è pacificamente ammessa quindi la sperimentazione a fini terapeutici, è invece esclusa la possibilità di utilizzare gli embrioni per fini differenti ${ }^{36}$.

II comma $4^{\circ}$ della stessa disposizione elenca poi gli embrioni che possono essere utilizzati a fini sperimentali. Si tratta di «a) Embriões criopreservados, excedentários, em relação aos quais não exista nenhum projecto parental; b) Embriões

\footnotetext{
${ }^{34} \mathrm{E}$ ciò sulla base della considerazione per cui «il vulnus alla tutela della dignità dell'embrione (ancorché) malato, quale deriverebbe dalla sua soppressione tamquam res, non trova [...] giustificazione, in termini di contrappeso, nella tutela di altro interesse antagonista».

35 Si noti che la Convenzione di Oviedo del 1997 ammette la ricerca scientifica condotta su embrioni in vitro. Nell'art. 18 del documento in questione si legge, infatti, che «1- Quando la ricerca sugli embrioni in vitro è consentita dalla legge, ciò garantirà un'adeguata protezione dell'embrione; 2- È vietata la creazione di embrioni umani a fini di ricerca».

36 La presente legge, peraltro, persegue l'uso abusivo di embrioni all'art. 40, che così dispone: «Quem, através de PMA, utilizar embriões na investigação e experimentação científicas fora dos casos permitidos na presente lei é punido com pena de prisão de 1 a 5 anos. Na mesma pena incorre quem proceder à transferência para o útero de embrião usado na investigação e na experimentação científicas fora dos casos previstos na presente lei».
} 
cujo estado não permita a transferência ou a criopreservação com fins de procriação; c) Embriões que sejam portadores de anomalia genética grave, no quadro do diagnóstico genético pré-implantação; d) Embriões obtidos sem recurso à fecundação por espermatozóide».

Pertanto, si può ritenere che la legge consenta l'uso di (alcuni) embrioni umani a fini di ricerca scientifica, in particolare nel contesto della terapia genica, purché non vi siano effetti sulla linea cellulare germinale e fintanto che la ricerca è diretta a scopi terapeutici, essendo stata esclusa la possibilità di utilizzarli in quella avente come finalità il "miglioramento" o la "valorizzazione".

In Italia, il Comitato nazionale per la bioetica, in un parere del 1991 ebbe modo di chiarire icasticamente i termini generali della questione dell'utilizzo degli embrioni individuando i limiti etico-giuridici di ammissibilità di interventi sugli stessi:

\begin{abstract}
«La terapia genica germinale presenta notevoli difficoltà tecnico-scientifiche ed è giustificabile, a parere del CNB, dal punto di vista etico-giuridico solo se presenta caratteri terapeutici sulla base del principio della intangibilità del patrimonio genetico della persona. Occorre tuttavia valutare attentamente $\mathrm{i}$ rischi di queste pratiche, perché tutti gli interventi correttivi eseguiti sulla linea germinale con materiale genetico estraneo, della stessa specie o di specie diverse, portano ad una modificazione della struttura e della organizzazione propria del genoma del soggetto, con conseguenze imprevedibili nello sviluppo della persona e della sua discendenza. La praticabilità della terapia genica somatica è invece meno problematica, in quanto non si discosta da altre forme di intervento terapeutico e deve sottostare soltanto ai criteri generali di ogni prestazione medica, per cui dovrà essere fondata su presupposti scientifici accertati, su indicazioni precise e sull'assenza di controindicazioni; potrà essere effettuata in assenza di terapie alternative sicuramente più efficaci e solo dopo aver acquisito il consenso informato del paziente. Qualora la terapia abbia carattere sperimentale, la valutazione dei rischi per il paziente dovrà essere condotta con assoluto rigore» ${ }^{37}$.
\end{abstract}

Per concludere, si può affermare che uno dei punti fissi rinvenibili a tutte le latitudini in materia è il divieto, sia a livello nazionale che internazionale, di pratiche sperimentali che prevedano (o presuppongano): la clonazione di embrioni animali, la creazione di chimere e ibridi, l'ectogenesi, nonché le terapie geniche germinali (benché si tratti di tecniche di fatto attualmente inapplicabili sull'uomo per varie ragioni, come l'alta percentuale di fallimento, i deleteri effetti collaterali e la limitata utilità pratica).

\footnotetext{
${ }^{37}$ Comitato Nazionale per la Bioetica italiano, Parere su "La terapia genica", del 15 febbraio 1991. Corsivi aggiunti.
} 


\section{4. "EUGENETICA DI STATO" ED "EUgenetICA PRIVATA", TRA "EDITING POSITIVO" ED "EDITING NEGATIVO". UN POSSIBILE BILANCIAMENTO TRA TUTTI GLI INTERESSI IN GIOCO.}

Quando si tratta il tema della terapia genica e della modificazione genetica, sorge sempre la domanda se, per tale via, non si stia promuovendo un vero e proprio eugenismo ${ }^{38}$.

La tecnica CRISPR-Cas9, come già accennato, è allo stato attuale oggetto di forte attenzione da parte dei ricercatori del settore, a ragione delle sue potenzialità in termini sia di miglioramento delle conoscenze di base dei processi di sviluppo cellulare, che di possibili applicazioni ad una serie di settori legati all'agricoltura, all'allevamento, alla biotecnologia industriale e, in generale, alle scienze della vita ed alle tecnologie applicate all'essere umano.

La letteratura scientifica internazionale, a tal riguardo, testimonia un particolare interesse verso le ricerche nell'ambito medico, dello sviluppo di farmaci, della biologia di base e in quello, particolarmente delicato, della riproduzione umana.

Peraltro, va ricordato che solo il $2 \%$ del genoma umano codifica per proteine (cioè è coinvolto direttamente nella produzione di proteine). Modificando questo $2 \%$ con il gene editing è possibile correggere geni-malattia o costruire modelli di malattia, addirittura modificare sequenzialmente più geni che agiscono in maniera additiva per dare origine a malattie complesse (in pratica è possibile modificare il patrimonio genetico delle cellule in vitro, cioè in laboratorio, oppure in vivo, cioè in modelli animali, introducendo le caratteristiche genetiche delle malattie ereditarie).

II gene editing può anche essere applicato al restante 98\% del genoma umano non codificante, un tempo impropriamente definito "DNA spazzatura", che ha però importanti funzioni regolatorie.

Poiché, come è stato detto, l'idea di introdurre alterazioni controllate nel genoma è presente da tempo, si presenta una questione fondamentale, che riguarda il modo di considerare questa tecnica innovativa: essa può essere vista come un nuovo strumento, migliore rispetto a quelli già disponibili, ma che non cambia il quadro generale relativo alla modificazione del genoma e alle sue prospettive; oppure come un

38 Su questo tema, v. Sánchez, F., "Diagnóstico Genético Embrionario y Eugenesia: un reto para el derecho sanitário", DS, 2007, num. 15 (1), pagg. 86 e ss.; e Beriain, I., Del Cano, A. M., Gene editing in human embryos. A comment on the ethical issues involved, in AA. VV., The Ethics of Reproductive Genetics (Marta Soniewicka ed.), Springer, 2017, pagg. 11 ss. 
mezzo dalle potenzialità di trasformazione talmente enormi da riconfigurare radicalmente le aspettative e le ambizioni nei confronti della scienza e delle sue capacità applicative.

Tuttavia, è forse necessario "demistificare" il significato che si accompagna all'uso di questa tecnica, senza dubbio offuscato dalle orribili pratiche eugenetiche condotte nella Germania nazista, negli Stati Uniti o persino nel Nord Europa (si pensi alla sterilizzazione forzata di donne con miopia).

II tema al quale si sta accennando in questo lavoro non riguarda una possibile "Eugenia of State", ma semmai la crescita e l'affermazione di una cosiddetta "eugenetica privata", consistente ad esempio nella possibilità per i genitori di scegliere i migliori geni possibili per i loro figli.

In effetti, è possibile identificare diverse pratiche eugenetiche che, in questo senso, sono consentite in Portogallo: ad esempio, la selezione dei donatori nella procreazione assistita medica; il metodo di iniezione intracitoplasmatica di spermatozoi; l'aborto, dopo la diagnosi prenatale, di feti affetti da patologie o malformazioni gravi ${ }^{39}$; la selezione di embrioni nella diagnosi genetica preimpianto ${ }^{40}$.

39 Del resto, non può essere trascurata una importante apertura registratasi proprio recentemente, da parte del Vaticano, sul tema. La "Nota sulla moralità dell'uso di alcuni vaccini anti-Covid-19", pubblicata dalla Congregazione per la dottrina della fede, ritiene moralmente lecito l'uso di vaccini prodotti mediante l'impiego di linee cellulari provenienti da tessuti ottenuti da feti abortiti, dal momento "che il tipo di cooperazione al male (cooperazione materiale passiva) dell'aborto procurato da cui provengono le medesime linee cellulari, da parte di chi utilizza i vaccini che ne derivano, è remota». Nel testo si legge, in particolare, che «il dovere morale di evitare tale cooperazione materiale passiva non è vincolante se vi è un grave pericolo, come la diffusione, altrimenti incontenibile, di un agente patogeno grave», ma «l'utilizzo moralmente lecito di questi tipi di vaccini, per le particolari condizioni che lo rendono tale, non può costituire in sé una legittimazione, anche indiretta, della pratica dell'aborto, e presuppone la contrarietà a questa pratica da parte di coloro che vi fanno ricorso». Dunque, stando al documento pontificio, l'illiceità morale delle attività di produzione, commercializzazione e somministrazione di vaccini ottenuti mediante l'uso di materiale embrionale umano, si configurerebbe allorché tali azioni muovessero dal considerare l'embrione umano alla stregua di un mero ed inerte cumulo di tessuto cellulare, misconoscendone la dignità sua propria.

40 Secondo gli artt. 28 e 29 della legge 32/2006: «1- L'obiettivo della DGPI è di identificare gli embrioni che non presentano un'anomalia grave, prima di trasferirli nell'utero della donna, usando tecniche di PMA, oppure per le finalità di cui al comma 3 dell'art. 7 ». Si aggiunge che: «1- La DGPI è rivolta a persone provenienti da famiglie con alterazioni che causano morte precoce o malattie gravi, quando vi è un alto rischio di trasmissione alla loro prole; 2- Le indicazioni mediche specifiche per possibili DGPI sono determinate dalle attuali buone pratiche e sono incluse nelle raccomandazioni delle organizzazioni professionali, nazionali e internazionali, e vengono periodicamente riviste». Nostra la traduzione italiana. II testo degli articoli summenzionati in portoghese è invece il seguente: Artigo 28. "Rastreio de aneuploidias e diagnóstico genético pré-implantação 1 - O diagnóstico genético pré-implantação (DGPI) tem como objectivo a identificação de embriões não portadores de anomalia grave, antes da sua transferência para o útero da mulher, através do recurso a técnicas de PMA, ou para os efeitos previstos no n. ${ }^{\circ} 3$ do artigo $7 .^{\circ} 2$ - É permitida a aplicação, sob orientação de médico especialista responsável, do rastreio genético de aneuploidias nos embriões a transferir com vista a diminuir o risco de alterações cromossómicas e assim aumentar as possibilidades de sucesso das técnicas de PMA. 3 É permitida a aplicação, sob orientação de médico especialista responsável, das técnicas de DGPI que

Revista de Direitos Fundamentais \& Democracia, Curitiba, v. 26, n. 1, p. 119-134, jan./abr. 2021. 
Pertanto, secondo alcuni studiosi, non solo "l'eugenetica privata" è già di fatto consentita e praticata, attraverso l'uso delle tecniche qui indicate, ma addirittura non sarebbe sostenibile la tesi secondo cui l'ammissibilità dell'uso dell'editing genetico potrebbe comportare la comparsa di un "nuova eugenetica di Stato".

Andrebbe anzi accettato l'editing genetico sia in senso positivo che negativo.

Il classico esempio di editing genetico in senso negativo è quello di una coppia di non udenti che vuole avere un figlio ugualmente sordo. Ciò significherebbe generare un bambino con alcuni limiti deliberatamente scelti per lui, come la sordità, la cecità, il nanismo o la depressione. E ciò appare, ovviamente, inammissibile secondo la dottrina più accorta, in quanto si tratterebbe di limitare, prima ancora della nascita, le possibilità che il bambino potrebbe avere durante la sua vita.

Per quanto riguarda l'editing genetico in senso positivo, invece, cioè il miglioramento dell'embrione, dotandolo di alcune caratteristiche positive, come un QI più elevato della media o di una maggiore forza fisica, continua a riscontrarsi comunque una profonda contrarietà da parte della dottrina maggioritaria.

Peraltro, questa pratica è finanche perseguita penalmente in Portogallo, con l'art. 37 della legge 32/2006, che punisce la selezione artificiale positiva ${ }^{41}$.

Anche in Italia, alla luce della menzionata Legge 40/2004, resta in vigore il divieto di manipolazione o selezione degli embrioni con finalità mere di potenziamento/accrescimento di facoltà o qualità individuali.

Su questo tema, peraltro, il Comitato di Bioetica del Consiglio d'Europa, nella sua Dichiarazione sulle tecnologie di modifica del genoma, del 2 dicembre 2015, ha evidenziato che l'uso delle tecnologie genoma editing

«è fortemente supportato, purché sia orientato verso una migliore

tenham reconhecido valor científico para diagnóstico, tratamento ou prevenção de doenças genéticas graves, como tal considerado pelo Conselho Nacional de Procriação medicamente Assistida. 4 - Os centros de PMA que desejem aplicar técnicas de DGPI devem possuir ou articular-se com equipa multidisciplinar que inclua especialistas em medicina da reprodução, embriologistas, médicos geneticistas, citogeneticistas e geneticistas moleculares». Artigo 29. "Aplicações 1 - O DGPI destina-se a pessoas provenientes de famílias com alterações que causam morte precoce ou doença grave, quando exista risco elevado de transmissão à sua descendência. 2 - As indicações médicas específicas para possível DGPI são determinadas pelas boas práticas correntes e constam das recomendações das organizações profissionais nacionais e internacionais da área, sendo revistas periodicamente».

${ }^{41}$ La menzionata legge 32/2006, art. 37 stabilisce che: «Quem utilizar ou aplicar técnicas de PMA para conseguir melhorar determinadas características não médicas do nascituro, designadamente a escolha do sexo, fora dos casos permitidos pela presente lei, é punido com pena de prisão até 2 anos ou com pena de multa até 240 dias». Ossia: «Chiunque usi o applichi tecniche di PMA per migliorare alcune caratteristiche non mediche del nascituro, vale a dire la scelta del sesso, al di fuori dei casi consentiti da questa legge, è punito con la reclusione fino a 2 anni o con una multa fino a 240 giorni». Nostra la traduzione. 
comprensione delle cause delle malattie e del loro futuro trattamento attraverso nuove tecnologie», e che «nonostante ciò, l'applicazione della tecnologia di editing del genoma ai gameti o agli embrioni umani solleva molti problemi etici, sociali e di sicurezza, in particolare per quanto riguarda la modifica che può essere trasmessa alle generazioni future».

Nel settembre 2017, anche il Deutscher Ethikrat ha espresso le sue preoccupazioni sull'uso della terapia genica, riferendo, in un'opinione, cauta ma puntuale, che

\begin{abstract}
«speculations now concentrate less on whether but rather only on when the first human genetically modified by genome editing will be born", e aggiungendo che "the German Ethics Council urgently recommends that the German Bundestag and the Federal Government take the initiative in the forthcoming legislative period to kick off an international debate on germline interventions in humans in order to establish binding global rules as soon as possible» ${ }^{42}$.
\end{abstract}

Negli Stati Uniti, la National Academy of Sciences e la National Academy of Medicine hanno stabilito che

\begin{abstract}
«gli interventi germinali, entro limiti di rischio rigorosamente regolati [...], erano eticamente difendibili se l'intervento costituiva davvero l'ultimo ragionevole opzione per una coppia di avere il proprio bambino biologicamente sano. [...] $\mathrm{Si}$ passa dal "non consentire fino a quando i rischi non sono stati chiariti", al "consentire se i rischi possono essere valutati in modo più affidabile" ${ }^{43}$.
\end{abstract}

Questi orientamenti potrebbero segnare l'inizio del cambiamento nel modo in cui la dottrina affronterà il problema?

Pur con la consapevolezza che esistono già molteplici posizioni autorevolissime espresse a livello internazionale, non appare del tutto azzardato ritenere di poter contribuire al dibattito, lanciando una provocazione che prende le mosse proprio dalla fonte primaria della health law, ossia la Dichiarazione dell'OMS del 1946, secondo la quale

«la salute è uno stato di completo benessere fisico, mentale e sociale e non consiste solo nell'assenza di malattia», e che "godere del miglior stato di salute che può essere raggiunto è uno dei diritti fondamentali di tutti gli esseri umani,

${ }^{42}$ Cfr. Deutscher Ethikrat, "Germline intervention in the human embryo: German Ethics Council calls for global political debate and international regulation. Ad hoc Recommendation", 2017, Berlin, pagg. 3 e 5.

43 National Academies of Sciences, Engineering, and Medicine, "Human Genome Editing: Science, Ethics, and Governance", 2017, Washington, D.C., apud Deutscher Ethikrat, op. cit., pag. 3. Nostra la traduzione dal testo in inglese che così recita: «[...] the recommendations drawn up in February 2017 by a committee jointly convened by the US National Academy of Sciences and National Academy of Medicine appear surprising. They advanced, for instance, the hypothesis that germline interventions, within strictly regulated risk limits and when coupled with accompanying research on the risk, were ethically defensible if the intervention constituted "really the last reasonable option" for a couple of having their own healthy, biological child [...].It switches from "not allowed as long as the risks have not been clarified" to "allowed if the risks can be assessed more reliably"». 
indipendentemente da razza, religione, credo politico, stato economico o sociale».

La domanda da porsi è se alla luce di tale dichiarazione, una coppia che voglia offrire al proprio figlio un "completo benessere fisico, mentale e sociale" (purché ciò sia, ovviamente, possibile e sicuro dal punto di vista tecnico) non debba essere legalmente messa in condizione di farlo. Parte della dottrina risponderebbe negativamente e aggiungerebbe che i padri e le madri pronti a far "modellare" l'embrione, al fine di garantire al nascituro le migliori caratteristiche psico-fisiche possibili, sarebbero del tutto assimilabili all'Homo Deus.

Una posizione moderatamente progressista (ma, mai troppo liberale ${ }^{44}$ ), forse da preferire, difende, invece, la visione secondo la quale i divieti categorici di intervento nella linea cellulare germinale debbano essere rivisti, in particolare quando sono in gioco malattie gravi, come la fibrosi cistica, poiché non potrà esserci in casi come questi una violazione della dignità umana o del diritto all'integrità fisica delle persone, ma potrebbe persino parlarsi di una piena promozione del diritto alla salute, previsto da tutte le Costituzioni più moderne.

L'argomento, spesso invocato strumentalmente, secondo il quale un approccio come questo costituirebbe una discriminazione nei confronti delle persone nate con disabilità (senza aver potuto godere di analoghi benefici) appare, quindi, da respingere.

L'esistenza di soggetti portatori di handicap o malformazioni non correggibili non dovrebbe mai impedire alla medicina di cercare di svilupparsi per evitare che in futuro altri individui possano trovarsi nelle stesse condizioni. Inoltre, spetta alla legge e alla comunità in generale garantire che le persone nate con disabilità si vedano riconosciute le cure adeguate ed una piena inclusione sociale, riducendo così quanto più possibile le conseguenze sfavorevoli derivanti dalle infelici condizioni di salute.

Vi sono anche coloro che invocano il cosiddetto "principio di precauzione", per osteggiare la possibilità di realizzare interventi come quelli menzionati. $\mathrm{Ma}$, a prescindere dal fatto che si tratta di un principio difficilmente riscontrabile nei vari testi costituzionali (sebbene sia previsto in molte legislazioni ordinarie), non pare che esso possa davvero essere interpretato e applicato in modo così rigido da originare un'autentica "euristica della paura".

Va semmai considerato, viceversa, il fatto che vietare in modo categorico

${ }^{44} \mathrm{Al}$ contrario, il più conservatore tenderà a rafforzare la necessità di mantenere il divieto legale contenuto nell'art. 8/2 della legge 12/2005 e della Convenzione di Oviedo. 
l'editing genetico degli embrioni umani potrebbe portare alla creazione di "mercati neri" o alla promozione indesiderata di "pratiche di turismo biotecnologico", alla luce anche dei costi relativamente bassi di queste tecniche (soprattutto se bilanciati con i promettenti risultati fin qui ottenuti) ${ }^{45}$.

Uno degli argomenti effettivamente più convincente tra quelli proposti da chi è contrario ad una posizione più liberale (o quanto meno invita ad affrontare il tema con estrema prudenza) riguarda, per un verso, la difficoltà di individuare con esattezza il confine tra "cura" e "potenziamento", e, per un altro, il rischio che (nonostante la summenzionata facile accessibilità dal punto di vista economico) si possano generare nuove e sempre più gravi forme di disuguaglianza umana e sociale (a meno che non si voglia davvero ammettere che l'editing genetico debba diventare a tutti gli effetti una prestazione sanitaria da fornire gratuitamente a tutti gli interessati da parte dello Stato).

La grande sfida del futuro, in materia, è probabilmente proprio questa ultima.

Ed è possibile invocare a tal fine una serie di norme specifiche e rilevanti contenute in documenti internazionali, come quelle dettate nell'art. 13 della Dichiarazione universale sulla bioetica e i diritti umani del 2005 (che parla di un dovere di solidarietà e cooperazione) ${ }^{46}$, nella Costituzione dell'OMS del 1946 (nella quale si menziona anche un dovere di cooperazione tra individui e Stati per raggiungere l'obiettivo di garantire la "salute di tutti i popoli", senza alcuna distinzione) e, infine, nell'art. 12 della Dichiarazione universale sul genoma umano e sui diritti umani del $1999^{47}$.

\section{CONCLUSIONI}

Per concludere, è possibile svolgere una sintesi della riflessione proposta, indicando quattro punti che sembrano fondamentali per provare a dare un piccolo contributo al dibattito su questo argomento così complesso e ricco di implicazioni etiche.

\footnotetext{
${ }^{45}$ Cfr. Beriain, I., Del Cano, A. M., "Gene editing", op. cit., pagg. 4-5.

46 Nella disposizione in questione si legge che «deve essere incoraggiata la solidarietà tra gli esseri umani e la cooperazione internazionale a tale scopo».

47 Secondo tale articolo, «a) I benefici dei progressi della biologia, della genetica e della medicina, relativi al genoma umano, devono essere resi disponibili a tutti, con la dovuta considerazione per la dignità e i diritti umani di ciascun individuo; b) La libertà di ricerca, necessaria per il progresso della conoscenza, fa parte della libertà di pensiero. Le applicazioni di ricerca, comprese quelle svolte nei settori della biologia, della genetica e della medicina, che coinvolgono il genoma umano, devono cercare di alleviare la sofferenza e migliorare la salute degli individui e dell'umanità nel suo insieme».
} 
1. È necessario, prima di tutto, discutere seriamente sul concetto generale di essere umano (e di embrione), vale a dire dal punto di vista biologico, etico, filosofico e giuridico.

2. È inoltre doveroso chiarire cosa si intenda per "salute" (e se la terapia genica sia ammessa solo per perseguire scopi terapeutici e di promozione della salute e sia vietata ogni volta che venga utilizzata oltre tale finalità) ed è indispensabile stabilire con nettezza quale sia la linea di confine tra le due ipotesi (ed evitare che approfittando delle "zone grigie" vengano commesse delle violazioni di legge).

3. Dopo aver deciso se e quali tipi di interventi potranno essere ammessi, ricorrendo alle nuove tecnologie di ingegneria genetica, occorrerà certamente evitare che ci siano soggetti nati sani grazie alla sola possibilità economica dei loro genitori (ed altri privi della stessa opportunità per ragioni di censo) o, peggio ancora, che vi siano "esseri umani di prima classe o migliorati" e soggetti di serie B, per colpe che non hanno e che sono ascrivibili alla situazione patrimoniale dei loro genitori.

4. Sebbene la delicatezza delle questioni etiche legate allo statuto dell'embrione e alla possibilità di effettuare ricerche su di esso non consentono di parlare al momento di un'armonizzazione reale ed effettiva delle discipline operanti a livello europeo, è, tuttavia, poco ragionevole pensare che in un'Europa unita - che ha l'ambizione di puntare ad una integrazione sempre più forte fra i suoi Paesi - si possa continuare a lasciare ai singoli Stati (ed in particolare ai loro legislatori o interpreti), una totale discrezionalità in materia, col rischio di un lex (o semplicemente forum) shopping o di fughe verso gli ordinamenti più progressisti (riservate, peraltro, solo a chi può economicamente permettersele $)^{48}$.

\footnotetext{
48 Come si legge nello Studio finale su "Le implicazioni etiche della ricerca sugli embrioni umani", pubblicato nel 2000 dalla Direzione Generale degli Studi, Divisione Industria, ricerca e energia STOA (Scientific and Technological Options Assessment) del Parlamento Europeo, op. cit, pag. 57, «In primo luogo si è affermato che i progressi della biomedicina hanno assunto un tale ritmo che le leggi dei vari Stati membri non riescono a tenere il passo con gli sviluppi. In secondo luogo, dato il ritmo sostenuto dello sviluppo e la frammentazione dell'approccio fra gli Stati membri, emergono preoccupazioni riguardo alla nascita di eventuali "paradisi" per la ricerca, dove gli scienziati potrebbero approfittare della mancanza di regolamentazione per eludere le restrizioni giuridiche in vigore nei loro paesi».
} 


\section{BIBLIOGRAFIA}

ALEXANDRE, H. L'expérimentation sur les embryons de mammifères. In: SUSANNE, $\mathrm{CH}$. (Dir). Les manipulations génétiques. Jsqu'où aller? Bruxelles. De Boeck Université, 1990. 77-78.

ARAKI, M., \& ISHII, T. "International regulatory landscape and integration of corrective genome editing into in vitro fertilization". In: Reproductive biology and endocrinology, 12 (1), 2014. 108.

ARCHER L. Terapia génica humana. In: GAFO, J. (ed.). Ética y biotecnología. Madrid. Publicaciones de la Universidad Pontificia de Comillas, 1993. 123-142

AUSSON, F. Se fabrican hombres. Informe sobre la genética humana. Madrid. Rialp, 1988. 131-132.

BERIAIN, I., \& DEL CANO, A. M. Gene editing in human embryos. A comment on the ethical issues involved. In SONIEWICKA, M. (Ed). The Ethics of Reproductive Genetics. Springer, 2017.

DEUTSCHER ETHIKRAT. "Germline intervention in the human embryo: German Ethics Council calls for global political debate and internationsl regulation”, Berlim, 2017.

DUNSTAN GR. "Pre-embryo research". In Journal of Assisted Reproduction and 
Genetics, 1995, 12 (8). 517-523.

FUKUYAMA, F. Our Posthuman Future: consequences of the biotechnology revolution. Londres, Profile Books LTD, 2002.

GOMES CANOTILHO, J. J., MOREIRA, V. Constituição da República Portuguesa Anotada. Vol I, $4^{\mathrm{a}}$ ed. Coimbra. Coimbra Editora, 2014.

GRACIA GUILLÉN D. Historia de la eugenesia. In GAFO, J. (ed). Consejo genético: aspectos biomédicos e implicaciones bioéticas. Madrid. Publicaciones de la Universidad Pontificia de Comillas, 1994. 13-34.

GREELY, H. T. "CRISPR'd babies: human germline genome editing in the 'He Jiankui affair"'. In Journal of Law and the Biosciences. 6 (1), 2019. 111-183.

GYNGELL, C., BOWMAN-SMART, H., \& SAVULESCU. "J. Moral reasons to edit the human genome: picking up from the Nuffield report". In Journal of medical ethics, 45(8), 2019. 514-523.

HABERMAS, J. The Future of Human Nature. Cambridge, UK. Polity Press, 2003.

HARARI, Y. N. Homo Deus: história breve do amanhã, Elsinore, 2017.

HUANG, J. ET AL. "CRISPR/cas9-mediated gene editing in human tripronuclear zygotes". In Protein Cell, 6 (5), 2015.

KANG, X. ET AL. "Introducing precise genetic modifications into human 3PN embryos by CRISPR/Cas-mediated genome editing". In Journal of Assisted Reproduction and Genetics, 33, 2016.

LACADENA, J. R. "Edicion genomica: ciencia y etica". In Revista Iberoamericana de Bioética, (3), 2017. 1-16.

LEROY, F. Fécondation in vitro humaine et génétique. In SUSANNE, CH: Les manipulations génétiques. Jusqu'où aller? Bruxelles. De Boeck Université, 1990. $99-111$.

LI, J. R., WALKER, S., NIE, J. B., \& ZHANG, X. Q. "Experiments that led to the first gene-edited babies: the ethical failings and the urgent need for better governance". In "Journal of Zhejiang University-SCIENCE B", 20 (1), 2019. 32-38.

LLEDÓ YAGÜE, La identificación de la persona mediante pruebas genéticas y sus implicaciones jurídicas. In El derecho ante el Proyecto Genoma Humano. Vol. IV. Fundación BBV. 1994. 14.

LÓPEZ MORATALLA, N. Experimentación en fetos humanos, IN LÓPEZ MORATALLA N Y COL. Deontología Biológica. Pamplona. Facultad de Ciencias Universidad Navarra, 1987. 293-303.

OLIVEIRAASCENSÃO, J. Estudos de Direito da Bioética, Vol. II, Almedina, 2008. 
ROCA TRIAS, E. "El derecho perplejo: los misterios de los embriones". In Rev Der Gen H. (1) 1994. 121-151.

SÁNCHEZ, F. "Diagnóstico Genético Embrionario y Eugenesia: un reto para el derecho sanitário", DS, 15 (1), 2007.

SANDER, J. \& JOUNG, J. K. "CRISPR-Cas Systems for editing, regulating and targeting genomes". In Nature Biotechnology, 32, 2014.

SAVULESCU, J. "Procreative beneficience: why we should select the best children". In Bioethics, 15 (5-6), 2001.

SAVULESCU, J. \& KAHANE, G. "The moral obligation to create children with the best chance of best life". In Bioethics, 23 (5), 2009.

SPERLING, K. "Ingenieria genetica y medicina genetica". In Ingenieria genetica y reproduccion asistida. Edición de Marino Barbero Santos, 1989. 110.

WANG, C., ZHAI, X., ZHANG, X., LI, L., WANG, J., \& LIU, D. P. "Gene-edited babies: Chinese Academy of Medical Sciences' response and action". In The Lancet, 393 (10166), 2019. 25-26.

Recebido em 08/04/2021

Aprovado em 27/04/2021

Received in 08/04/2021

Approved in 27/04/2021 